\title{
Natureza e naturalização da tecnologia: panorama informacional na sociedade pós-medial
}

\author{
Nature and naturalization of technology: informational panorama in post-medial society
}

\author{
Giulia Crippa \\ Università di Bologna, Italia \\ giulia.crippa2@unibo.it \\ (iD https://orcid.org/0000-0002-6711-3144
}

\begin{abstract}
Resumo:
Depois de quase trinta anos de uso capilar das tecnologias de informação e comunicação (TICs), a sociedade tem naturalizado sua presença. Todavia, viver com as TICs não significa compreender o porte das mudanças paradigmáticas que elas realizaram globalmente. O objetivo desse artigo é discutir as premissas e as implicações das transformações socioculturais impostas pelas novas mídias, observando alguns de seus efeitos nas esferas social, econômica e política. A metodologia utilizada é de natureza qualitativa e bibliográfica, com uma discussão elaborada através das ferramentas dos estudos culturais e da sociologia do imaginário de matriz durandiana. Nossos resultados, a partir do filme Avatar, consideram os fenômenos de mudanças e transformações proporcionados em todas as esferas sociais pela naturalização da tecnologia nos discursos contemporâneos. Na discussão, oferece-se um percurso histórico sobre a evolução da mídia até a definição de um paradigma pós-medial; observam-se os efeitos da naturalização das TICs nos planos social, econômico e político; analisam-se os efeitos sobre o imaginário provocados pelo uso de terminologias improntadas na ideologia e na retórica da inovação; esboçam-se algumas respostas oferecidas pela sociedade e pela política aos problemas suscitados pelas TICs. Conclui-se que há uma necessidade de apropriação crítica das TICs, que necessariamente devem voltar a serem desnaturalizadas para se tornar objeto de estudo com foco mais amplo e não somente aplicativo.

PalaVras-Chave: Estudos informacionais, Tecnologias da informação e da comunicação, Paradigma pós-medial, Mudanças sociais, Economia informacional.
\end{abstract}

\begin{abstract}
:
After almost thirty years of capillary use of information and communication technologies (ICTs), society has naturalized its presence. However, living with ICTs does not mean understanding the scale of the paradigmatic changes they have made globally. The purpose of this article is to discuss the premises and the implications of the socio-cultural transformations imposed by the new media, observing some of their effects in the social, economic and political spheres. The methodology used is of a qualitative and bibliographic nature, with a discussion elaborated through the tools of Cultural Studies and Sociology of the Imaginary of Durandian matrix. Our results, from the movie Avatar, consider the phenomena of changes and transformations provided in all social spheres by the naturalization of technology in contemporary discourses. In the discussion, a historical path is offered on the evolution of the media until the definition of a post-medial paradigm; the effects of the naturalization of ICTs at the social, economic and political levels are observed; the effects on the imaginary caused by the use of improper terminologies in the ideology and rhetoric of innovation are analyzed; some responses offered by society and politics to the problems raised by ICTs are outlined. We conclude that there is a need for critical appropriation of ICTs, which must necessarily be denatured again to be the object of study with a broader focus and not just application.
\end{abstract}

KEYWORDS: Information studies, Information and communication Technologies, Post-medial paradigm, Social changes, Informational economics.

\section{INTRODUÇÃo}

Se a tecnologia é presença constante na dimensão histórica, a tecnologia digital tornou-se parte integrante da vida contemporânea já em boa parte do mundo. 
Os números nos falam isso, como se vê por alguns dados: em 2019 foram contabilizados, no mundo, 4,4 bilhões de usuários de Internet, que representa o $57 \%$ da população mundial, com um incremento de mais de um milhão de novos usuários todo dia. A distribuição geográfica da conexão é desigual, mas mesmo nos espaços onde o número de usuários é muito menor, como na África, que representava o 36\% do total, observou-se como mais de $80 \%$ da população tinha acesso a alguma rede móvel e que o incremento de pessoas conectadas dobrava ou triplicava todo ano. A mídia social, também, apresenta dados impressionantes: 45\% da população mundial ne faz uso, e nos últimos cinco anos o número de usuários dobrou (Starri, 2019).

Com o avanço das novas tecnologias de informação e comunicação (TICs), acentuam-se as mudanças nas formas de organização, tanto do mercado, quanto das relações de trabalho. Almeida e Crippa (2009), ao analisarem essa questão, destacam o seguinte:

As novas tecnologias impõem uma reorganização da informação não mais ligada à estrutura física de bibliotecas tradicionais e arquivos: a área de informação é responsável pela preservação, distribuição e acesso à informação, tanto para públicos especializados como para a população em geral. Todavia, isso não se realiza através de princípios de ordem aleatórios, mas sim relacionados com as instituições e empresas interessadas na produção e disseminação da própria informação.

“[...] a tecnologia é mais que um conjunto de técnicas, trata-se de todo um sistema de relações sociais, com amplas repercussões na constituição da própria sociedade. [...] A tecnologia modifica/redimensiona nossa visão de mundo" (Almeida e Crippa, 2009, p. 124).

Sobre o campo da ciência da informação (CI), os autores fazem uma abordagem do papel do cientista da informação como mediador, afirmando que:

[...] o cientista da informação está empenhado na construção de ferramentas classificatórias no horizonte dos novos suportes tecnológicos, tornando-se, nesse sentido, mediador para os usuários, desenhando, através das ferramentas, a configuração do que seu tempo e sua sociedade definem como ciência [...] Como mediador, o cientista da informação poderia, portanto, contribuir para a ampliação e melhoria desse diálogo. (Almeida e Crippa, 2009, p. 125).

Nesse sentido, Lastres e Albagli (1999) explicam que:

Do ponto de vista econômico, verificam-se novas práticas de produção, comercialização e consumo de bens e serviços, cooperação e competição entre os agentes, assim como de circulação e de valorização do capital, a partir da maior intensidade no uso de informação e conhecimento nesse processo. Tais práticas apoiam-se, por sua vez, em novos saberes e competências, em novos aparatos e instrumentais tecnológicos, tanto como em novas formas de inovar e de organizar o processo produtivo, expressando-se assim uma nova economia ou um novo padrão técnico- econômico e ensejando também a necessidade de novas abordagens na própria teoria econômica e do valor. (Lastres e Albagli, 1999, p. 8).

Portanto, caberia aos profissionais da informação construir catálogos e/ou buscadores cada vez mais detalhados e sofisticados. Mas essa proposta de competências, que atribui essas tarefas e pouco mais aos profissionais, é realmente sustentável, perante a nova configuração estrutural definida pelas próprias TICs? Nosso objetivo, neste texto, não é aprofundar a gênese ou o desdobramento desses processos, mas, a partir de uma cartografia exploratória, investigar algumas experiências capazes de confirmar a relação que se estabelece atualmente entre a tecnologia e a sociedade que, cada vez mais, vem sendo definida "pós-medial". Lemos (2011) resume essa relação da seguinte forma:

Em suas dimensões física (transporte de pessoas, objetos, commodities) e informacional (sistemas de comunicação), a mobilidade cria uma dinâmica tensa entre o espaço privado (a fixação) e o público (a passagem, a efemeridade), entre o próximo e o distante, entre curiosidade e apatia [...]. É nesse movimento que se produz a política, a cultura, a sociabilidade, a subjetividade, (Lemos, 2011, p. 16).

Partimos da hipótese de que esses processos de transformação simbólica operam em uma dialética entre dois polos: de um lado, certa recusa ou reticência em relação à tecnologia em favor de uma experiência autêntica de resgate da tradição; de outro, a perspectiva de usar a tecnologia como possibilidade de resgate/ 
preservação do passado. É, claro, uma oposição "ideal", em termos weberianos - sabemos que não existem tais extremos na realidade empírica. Apesar disso, essa oposição é útil para situar as experiências que iremos analisar em um continuum e observar suas ambiguidades.

Se for opinião compartilhada dizer que o mundo moderno - em termos de um cotidiano marcado pela presença de bens e serviços urbanos - remonta ao século XIX, mesmo período em que Marx afirmava que "tudo o que é sólido desaparece no ar", é também verdade que o desenvolvimento das TICs que compõem palavras, sons, imagens se tornam bytes, com consequências notáveis: o computador se torna uma "metamídia”, isso é, uma máquina capaz de reproduzir, combinar e conectar produtos de mídias deferentes (Jenkins, 2009). Esse "desmantelamento", entendido como a desconstrução dos antigos modos de vida, encontra um de seus arquitetos na tecnologia e, ao longo do século XX, observa-se como essa tendência só se aprofundou. Os anúncios pioneiros de eletrodomésticos, em sua pedagogia voltada para as donas de casa de classe média, ilustram a força dos valores do que se considerava uma casa "moderna". Desenvolveu-se também uma sensibilidade antagônica e complementar, que consiste no aprimoramento da tradição, talvez reflexo do desejo de rotina e hábitos considerados estáveis em um mundo revolucionado por contínuas inovações e mudanças.

Neste artigo, a partir de algumas representações das novas TICs, queremos entender como o discurso sobre as mesmas reflete as transformações estruturais por elas produzidas.

\section{Metodologia}

Para esse estudo, de natureza qualitativa e bibliográfica, utilizamos uma metodologia ligada aos Estudos Culturais, com o objetivo de traçar uma topografia das interações entre a tecnologia como objeto de narrações e seus efeitos no contexto das práticas sociais. O primeiro movimento do trabalho busca, assim, configurar uma representação do imaginário sobre o tema da tecnologia em relação à informação.

Analisar produtos culturais como séries de TV ou filmes torna-se ponto de partida particularmente interessante quando observamos o impacto dos discursos sobre tecnologia e sua implementação no âmbito dos processos de produção do capitalismo tardio.

É importante explicitar alguns conceitos teóricos aos quais aderimos, já que um repertório de imagens é oferecido como exemplo de índice de processos simbólicos, ideológicos e representativos. A relação das imagens com o campo do imaginário já foi objeto de ampla discussão para Le Goff (1993). Entre permanências e transformações - lembrando Durand (2012), segundo o qual crenças coletivas não são substituídas se uma sociedade não consegue criar novas - as imagens revelam aquele espaço no qual a ideologia, como relação social, entra na esfera do imaginário na relação que esse estabelece com a realidade.

Novamente, partindo da obra de Durand, o artigo visa oferecer a polissemia de imagens portadoras do mesmo símbolo; observar suas elaborações, para compreender como são capazes de explicar sua apropriação e "reuso" heterogêneo no tempo e no espaço e, por fim, a difusão dos temas simbólicos oferecidos às apropriações socioculturais.

\section{Resultados: UMA VISÃo ECO-FRIENDLY DA REDE OU A NATURALIZAÇÃo DA TECNOLOGIA}

Um dos produtos mainstream de maior sucesso da primeira década do século XXI é o filme Avatar, de James Cameron, ganhador do Oscar em 2009. A história é bem conhecida: os humanos, dotados de recursos tecnológicos muito avançados, se voltaram para a conquista de novos mundos, em busca dos recursos necessários para prosseguir em seu desenvolvimento. Uma conquista predatória e violenta, como podemos ver na atuação de uma grande corporação de mineração, que se vale de uma estrutura militar para a obtenção do controle do planeta Pandora. Para obter o unobtanium, recurso indispensável para a colonização 
interplanetária, é necessário não somente comprometer, mas subverter completamente a ordem e o equilíbrio naturais de Pandora. Esse equilíbrio compreende as populações nativas, os $\mathrm{Na}$ 'vi, humanoides azuis cujos corpos, altos quatro metros são geneticamente imitados pela tecnologia humana, em busca da contatos "antropológicos" por parte dos cientistas que acompanham as expedições de conquista e colonização. Até a chegada de Jack Sully, ex-militar paraplégico que em Pandora deve "ocupar" um desses avatares com a estrutura dos nativos, a comunicação entre os humanos e os Na'vi não tinha tido muita eficácia. Jack, porém, se apropria de maneira profunda de seu novo corpo, que governa através de uma conexão neuronal "tecnológica" O aparelho que lhe permite dar vida ao avatar é um casulo metálico, externo ao corpo e claustrofóbico, onde não é possível permanecer o tempo inteiro. Jack, aos poucos, ganha a confiança dos $\mathrm{Na}$ 'vi e aprende cada dia mais as facetas da cultura de suas comunidades. Os $\mathrm{Na}$ 'vi vivem caçando e colhendo os frutos do planeta, são armados de arcos e flechas e domesticam alguns animais para cavalgar e sobrevoar o planeta. Os membros das tribos se conectam com seus animais e, durante as cerimônias coletivas, com uma verdadeira rede, cujo provedor é a árvore de E’wa e cujas conexões atravessam o planeta inteiro. Com essas informações que transmite ao chefe das milícias corporativas, Jack trai o $\mathrm{Na}$ ’vi, permitindo que as máquinas destruam E'wa. Somente em um segundo momento Jack se resgata de sua traição, encabeçando a resistência dos Na'vi. No final, a integração definitiva de Jack aos Na'vi se dá na medida em que ele renuncia ao seu corpo humano e, através da mediação dessa rede biológica, sua mente pode ocupar definitivamente o avatar.

A um primeiro olhar, o tema principal que atravessa o filme é a dialética extrema entre tecnologia e cultura: a tecnologia, humana, representada nos moldes de uma cultura científica oitocentista, busca dominar e eliminar a natureza, sem se preocupar com a sobrevivência do planeta, para extrair o unobtanium.

A natureza, porém, alcança dentro da narrativa seu triunfo discursivo, na representação da resistência de todos os organismos do planeta que, unidos, derrotam o invasor. Essa vitória é o resultado da integração de todos os organismos vivos que se realiza através das conexões com o próprio planeta.

Assim, essa narrativa, que aparentemente fala da disputa entre tecnologia e ambiente, constrói uma metáfora linear, na melhor tradição hollywoodiana (Banti, 2017), com a resolução final dos conflitos e a proposta de um mundo melhor, encena e declina de maneira bastante clara esse tipo de dialética tecnologia versus natureza. Essa construção discursiva, porém, nos leva a observar um outro aspecto, a nosso ver bem mais complexo: nos leva à produção de um discurso que mostra a naturalização estrutural das TICs. De fato, todo o sistema de Pandora se sustenta na base de uma distribuição em rede dos conhecimentos coletivos. A árvore sagrada, E’wa, se torna o grande provedor biológico quer preserva e distribui os dados de memória dos antepassados, ao qual todos podem atingir e para o qual são feitas circular aquelas informações que cada nova conexão fornece. Uma inteligência coletiva que se estrutura como imensa rede global, sempre acessível e, principalmente, parte essencial, natural, do funcionamento do sistema. A narrativa profunda do filme se torna, assim, a naturalização da vida integrada às TICs, baseada na hiper-sociabilidade de todos os membros.

Nossa relação com a tecnologia atravessa as formas do imaginário - não por acaso, muitas vezes, as tecnologias têm sido antes representadas nas ficções do que realizadas. Mas a tecnologia nos muda, definindo novas práticas e hábitos individuais e sociais. $\mathrm{Na}$ medida em que existe a rede e levamos junto ao corpo os instrumentos para acessá-la de qualquer lugar a qualquer momento, as formas anteriores de circulação da informação se tornam insatisfatórias: a existência das novas TICs mudou até a natureza dos conflitos e das relações internacionais, tornando necessário refletir de que forma isso aconteceu. Se não enfrentarmos um processo de desnaturalização de seu uso, não teremos a possibilidade de formular perguntas, hoje mais que necessárias, sobre ela. 


\section{Discussão}

\subsection{Dos dispositivos mediais à pós-medialidade}

O ponto de partida desse trabalho é que, a nosso ver, hoje vivemos em uma condição que superou a ideia que se originou entre os séculos XIX e XX, para nos encontrarmos em um paradigma novo, pós-medial, em que o computador, permitindo a convergência digital, de fato desempenha a função de "meta-mediação", incluindo e permitindo trocas entre todas as mídias anteriores.

No contexto da primeira Revolução Industrial, podemos identificar dois fenômenos em destaque:

1) A produção industrial e serial de objetos;

2) O novo cenário central da vida moderna, representado pela realidade urbana.

Essas duas transformações, de fato, estão conectadas, como se pode ver pela primeira Exposição Universal de Londres, em 1851 (Massidda, 2011), seguida, um ano depois, pela inauguração da primeira loja de conveniência em Paris, o Le Bon Marchè. É nesse contexto que devemos observar a industrialização da produção cultural, através de processos que envolvem tecnologias de criação, produção, exibição e distribuição que, por sua vez, modificam as características dos públicos.

O primeiro setor a ser envolvido na inovação industrial, do ponto de vista cultural, é o da reprodução da palavra impressa. De fato, com as novas tecnologias (que permitem uma mais ampla disponibilidade de papel e um sistema de impressão mais econômico), cria-se um novo público "urbano" de leitores, que é, ao mesmo tempo, de massa e que tem acesso a formas literárias de gêneros diferentes (literatura sentimental, de aventura e, no final do século XIX, policial). Importante é destacar a relevância que adquirem os editores que, sensíveis aos gostos modernos, com frequência passam a encomendar as obras aos autores. A partir da década de 1860, com o aperfeiçoamento dos sistemas de impressão dos jornais, esses se tornam meios de divulgação de notícias sensacionalistas e de folhetins, que permitem a contaminação entre gêneros diferentes (história, crônica, ficção), que não somente atraem a atenção dos leitores, como também se tornam formadores de seus gostos e cultura. No final do século, a produção cultural se amplia ainda mais, com as novas possibilidades oferecidas pela reprodução de difusão de imagens em movimento e de sons (Briggs e Burke, 2002).

Nesse contexto, nascem também as histórias em quadrinhos, quando, em 1895, inicia a publicação de Yellow Kid, de Richard Outcault (Hajdu, 2008).

O que nos interessa destacar aqui, nessa rápida e incompleta lista de inovações, é que o nascimento da mídia moderna é determinada pela introdução de dispositivos específicos, entendendo, com esse termo, não somente os instrumentos técnicos mas, de forma bem mais ampla, as situações sociais especificamente dedicadas ao consumo de produtos mediais: as formas de leituras (individuais e coletivas), as modalidades de execução de música gravada (em espaços públicos e privados), as de projeção e visão de filmes. O que se encontra é, em tudo isso, o uso de instrumentos tecnológicos, que envolvem a reprodução automatizada de palavras, sons e imagens. Dessa maneira, o corpo do público entra em uma relação simbiótica com tais dispositivos tecnológicos. Como consequência disso, as situações sociais dedicadas ao consumo desses produtos culturais se tornam de massa e serializadas: elas permitem que multidões tenham acesso a tipologias de experiência planejadas e reguladas que se torna idêntica e repetível, despojada, assim, de características de unicidade e privacidade. Ainda assim, os produtos culturais mantêm seu fascínio, envolvendo cada um dos espectadores que participa, que terá sua experiência individual.

A segunda fase da trajetória das mídias tradicionais, que vai da virada do século XIX para XX até a década de 1980, mostra, de um lado, o desenvolvimento tecnológico da indústria cultural e, do outro, a racionalização de suas atividades produtivas e de distribuição, essas últimas bem visíveis, por exemplo, no campo da indústria do cinema. A partir da década de 1920 ela se torna uma indústria rigidamente organizada, come se observa 
na estruturação do sistema de estúdios de Hollywood. Mas não se trata somente da produção. É preciso lembrar, de fato, que para serem vistos, os filmes precisam de um sistema de salas, que se desenvolve nessa fase: elas se tornam lugares de consumo rituais, ao mesmo tempo públicos e para o aproveitamento individual, que deslocam os indivíduos de seus lugares de trabalho ou de vida doméstica. A essa mudança de hábitos culturais une-se o aparecimento primeiro do rádio e, em um segundo momento, da televisão, que representam a expressão mais avançada de distribuição de mensagens através de redes capazes de penetrar de forma capilar os espaços sociais e, em particular, os espaços domésticos.

Quando se fala em rede, imediatamente pensamos em algo bem contemporâneo, mas, na verdade, no passado, as redes de distribuição de mensagens já eram de muitos tipos: redes viárias, ferroviárias, redes de telegrafia e, em seguida, de telefonia (Mattelart, 2002). A essas redes tangíveis, devem se somar as redes comerciais, que incluem a distribuição de discos (a partir de 1895), de livros (com a invenção dos tascáveis isso alcança grandes números na década de 1930). A invenção do rádio e da televisão, porém, mostram uma tipologia distinta de rede, que se torna independente de uma conexão estritamente material, com o aparecimento da rede de broadcasting, que caracteriza essa segunda onda de desenvolvimento da mídia.

Ela introduz uma forma inovadora de discurso midiático. Se na fase anterior, de fato, a mídia utilizava um discurso linear, moldado no modelo do texto, com começo, meio e fim, o broadcasting introduz algo radicalmente novo. o fluxo ininterrupto de sons e imagens, que ocupa as vinte e quatro horas do dia e que invade o tempo social e doméstico, marcando o tempo do trabalho e do lazer e seus horários mais marcantes e secundários, através da própria programação.

O que se torna evidente, em tudo isso, é que tanto a presença de mídias dotadas de lugares específicos (por exemplo, o cinema), tanto aquelas domésticas, tornam perceptível a presença desses aparatos na sociedade, permitindo a McLuhan (2011) entender seu enorme poder. As mídias de massa são capazes de influenciar de maneira vertical os gostos sociais dos públicos, seus interesses culturais e de moldar seu imaginário, bem como influenciar seus consumos e ideologias.

O que nos interessa, aqui, é a questão chave dos dispositivos midiáticos que introduzimos antes, que se encontram no centro de um processo dúplice: de um lado, esses dispositivos se multiplicam e se inserem de maneira capilar no tecido social, chegando nos lares e reconfigurando as formas de viver comum; do outro, os dispositivos, diferentes entre eles, são individualizados e reconhecíveis, no sentido que são percebidos como diferentes em relação às situações que não se relacionam às mídias da vida social. Ir ao cinema ou ligar o rádio são atos acompanhados de rituais que marcam o acesso a tempos e espaços de relação com esses meios.

A partir de meados da década de 1980 assiste-se a um conjunto de fenômenos que levam, a nosso ver, ao fim da mídia tradicional. Em primeiro lugar, há uma multiplicação dos canais de distribuição dos produtos da mídia, bem como de ocasiões de acesso a elas, com um grande aumento de disponibilidade de canais de rádio e TVs; novos dispositivos tecnológicos (ainda analógicos) se tornam disponíveis, liberando os públicos do tempo da programação, como aparelhos analógicos para videocassetes, bem como do espaço em que as mídias estavam fisicamente instaladas (é o caso do walkman). Paralelamente, assiste-se ao desenvolvimento das tecnologias digitais, que culminam com o surgimento da World Wide Web, implementada em 1989 (Castells, 2001).

A partir da década de 1990 assiste-se ao fenômeno da digitalização dos materiais que compõem os produtos culturais: palavras, imagens e sons passam a ser codificados em bytes, tornando-se informação que pode ser manipulada, memorizada e transmitida de maneira idêntica e de forma praticamente instantânea. $\mathrm{O}$ desenvolvimento das técnicas de digitalização implicou em uma mudança decisiva: os materiais mais diversos, veiculados pelas mídias tradicionais, são reduzidos a partículas de informação consideradas significantes, entrando na esfera de atuação da disciplina que se ocupa do tratamento da informação em base numérica, a chamada informática. 
As consequências desse deslocamento são conhecidas, a primeira delas sendo o surgimento de uma metamídia, o computador, isso é: uma tecnologia capaz de reproduzir, combinar e relacionar entre si produtos originários de mídias diferentes.

Portanto, se na primeira fase de desenvolvimento da mídia predomina o texto linear e finito e na segunda o fluxo linear e infinito, nessa última fase encontramos o modelo do hipertexto multimídia, que é reticular e infinito.

Dois aspectos muito importantes caracterizam os materiais digitais: cada cópia é indistinguível do original e ela pode ser manipulada e modificada por qualquer um que possua os instrumentos tecnológicos necessários para tanto. Ainda, depois de ter feito isso, pode distribuir esse trabalho pela web. Em outras palavras: com a tecnologia digital, a hierarquia entre emissor e receptor, que caracterizava as mídias anteriores, é eliminada. $\mathrm{O}$ emissor possui só em parte o original, enquanto o receptor adquire algumas funções de coautoria e distribuição, tornando-se o que Jenkins (2009) chama de prosumer.

\subsection{A condição pós-medial}

Afirma-se, antes, que nas mídias desenvolvidas principalmente ao longo do século XX os dispositivos midiáticos alcançaram um equilíbrio entre sua intervenção no social e a experiência individual. $\mathrm{O}$ que se observa nessa última faze é que esse equilíbrio se rompeu e um novo paradigma se estabeleceu, na medida em que a disseminação profunda na sociedade leva a uma perda de individualidade dos próprios dispositivos. Vamos, portanto, detalhar esse processo, no qual a perda dessas fronteiras entre dispositivos midiáticos define o paradigma pós-medial:

1) Se perde a distinção entre os dispositivos do passado. $\mathrm{Na}$ base dessa perda, encontra-se a própria evolução tecnológica, pois todos os dispositivos se fundamentam, hoje, no digital. Assim, entre um filme e um programa televisivo que pode ser assistido pelo tablete, não há uma distinção clara, tendo como efeito a chamada convergência digital (Jenkins, 2009).

2) Alguns dispositivos tradicionais são deslocados em espaços e situações aos quais não pertencem originariamente. Pensamos na presença de dispositivos cinematográficos quando transferidos em espaços públicos, como no caso dos videowalls, o de seu uso em museus, meios de transportes, celulares.

3) Os dispositivos mediáticos não perdem somente suas fronteiras em relação uns aos outros e ao seu uso originário. Passam, também, a integrar de maneira nova outros dispositivos, como no caso daqueles de controle social, que, em sua formulação, não tinham relação com as mídias. Pensamos, por exemplo, aos dispositivos de vídeo segurança, integrados às redes de comunicação, bem como na troca intensiva de dados e informações os quais, por outro lado, fornecem novas formas expressivas aos produtos da indústria cultural (cinema, reality shows, séries TV). De maneira similar agem os dispositivos de gravação de capacetes militares, ou de carros e motos de corrida; de controle e gestão dos ambientes domésticos; de interação conversacional; de trocas comerciais de bens e serviços.

Em outras palavras, não é mais possível, hoje, estabelecer o que é a mídia ligada à produção cultural e o que não é, nem quando acessamos os lugares e tempos da cultura (independentemente de sua qualidade). De fato, estamos imersos em sistemas e ambientes de relaçóes e trocas, utilizando os recursos que esses ambientes oferecem para alcançarmos nossos objetivos e assumindo papeis e posições que correspondem ao uso que tais recursos implicam. A mídia, hoje, é onipresente, e nós mesmos nos tornamos mídia. Nesse sentido, a mídia como a conhecíamos não existe mais: a condição pós medial nasce de uma acumulação quantitativa de mídias, cujo resultado é uma mudança qualitativa. As mídias, que perderam sua individualidade, "desapareceram" em uma rede de aparatos, de processos e práticas sociais quotidianas que tornam impossível isolar os componentes da mídia daqueles puramente tecnológicos. Um passo fundamental tem sido a naturalização 
da tecnologia, que nos conta da chegada de um conjunto de aparatos que não se opõe mais, como no passado, à naturalidade dos sujeitos que os utilizam, mas que se tornam capazes de constituir um mundo naturalcultural, nos obrigando a redefinir a interação entre téchne e bios, individualizando o desenvolvimento simultâneo de corpos e máquinas.

Nessa perspectiva, a naturalização da tecnologia se oferece como particularmente propícia ao ocultamento de uma lógica de mercado, que promove formas de hiperconsumo através das tecnologias, em um nível tal que não conseguimos, sequer, perceber os próprios atos de consumo. Por exemplo, a desmaterialização dos atos de pagamento é representativa dessa situação, na medida em que se realizam de maneira "invisível". Ainda, podemos considerar as lógicas distintas entre conteúdos adquiridos por empresas ou consumidores (paid), produzidos por elas (owned) ou recebidos de maneira aparentemente gratuita (earned), através da concessão dos dados dos usuários. Essas formas revelam em que medida as transações se realizam através fluxos de informações sobre nós mesmos, nossos gostos e nossos comportamentos em rede.

Para entender o significado disso e, nesse sentido, voltar ao questionamento do papel do cientista da informação dentro desse novo paradigma, vale a pena observar esses três exemplos:

1) O maior banco de dados global sobre gostos e consumos no campo cultural nos fala da ficção cinematográfica e televisiva, mídias que convergiram nas plataformas digitais. Trata-se da Netflix, que distribui online conteúdos. A plataforma monitora não somente quais filmes e séries entram no gosto do público, mas também quais cenas individuais são vistas mais vezes e quais não são assistidas. É difícil imaginar o tamanho desse patrimônio de big data e seu valor.

2) A geografia dos residentes em muitas cidades do mundo, destinando bairros inteiros ao turismo, tem sido mudada por Airbnb. Tecnologias, serviços e plataformas dessa natureza tiveram seu sucesso por permitirem o acesso a contatos, informações e produtos quer, antes, eram muito caros e inacessíveis para a maioria das pessoas. Mas isso provocou mudanças econômicas e sociais de grande porte. Consideramos, por exemplo, as perdas que os hotéis tradicionais tiveram com o aparecimento de Aibnb: para um turista, as ofertas da plataforma permitem uma mobilidade antes limitada pelos custos altos ou os serviços limitados. Mas o impacto é mais profundo, pois os danos investem os moradores das cidades, ou os estudantes universitários, que não encontram moradias estáveis, enquanto os lucros dados pela oferta turística impactam, também, o recebimento de impostos por parte das administrações públicas, que não conseguem ter o controle. Por outro lado, um dos problemas que muitas cidades turísticas vivenciam se devem ao excesso de visitantes, que as estruturas existentes não conseguem sustentar (problemas com redes de distribuição de água, esgoto, energia...). A história desse "sucesso", porém, serve para entendermos melhor a interdependência das tecnologias. De fato, a inovação que leva ao desenvolvimento de Airbnb é a das viagens aéreas low-cost, que surgem na Europa no começo da década de 1990 (antes da disseminação de Internet). Essa tipologia de viagem teve um impacto enorme na economia (com o desenvolvimento vertiginoso da indústria turística) e no ambiente, graças às mudanças sociais e políticas em andamento, como a abertura dos mercados à concorrência e o desenvolvimento de intercâmbios universitários - considerando que os jovens que participaram do projeto Erasmus tinham a necessidade de se deslocar sem grandes gastos. Além de reduzir os custos das viagens, aumentando assim o número de viajantes, os voos low-cost colocaram no mapa lugares até então quase desconhecidas ao turismo de massa. O desenvolvimento da web, logo em seguida, favoreceu o sucesso das novas companhias aéreas, pois, além de provocar a desintermediação entre a compra das passagens e os turistas, permitiu economizar confiando uma série de operações aos passageiros que anteriormente eram desempenhadas pelo pessoal de terra, como a realização do check-in, enquanto uma série de serviços pagos vinham sendo propostos. O sentido das mudanças econômicas pode, assim, ser considerado de maneira mais clara, observando inclusive como serviços dessa natureza (Aibnb, Flixbus, Blablacar, entre os muitos outros) transformam a mobilidade, o sentido das viagens, a percepção dos espaços urbanos.

3) Amazon tem redefinido a existência do comércio local, portanto da economia, modificando a estrutura dos centros urbanos, onde as lojas do pequeno comércio desaparecem, em favor da abertura de bares e 
restaurantes. Ainda, os serviços de entrega a domicílio de comida refletem e modificam os próprios hábitos alimentares, além de gerar trabalho precário e desvalorizado.

\subsection{A língua da tecnologia naturalizada e o imaginário}

Quanto mais uma tecnologia se dissemina e se populariza, tanto mais cresce sua capacidade de se tornar necessária e de ser naturalizada. Isso contribui em tornar muito difícil, para os usuários, discernir as implicações em termos de privacidade e de acessibilidade e compartilhamento de seus dados. Considera-se o seguinte: boa parte dos usuários de instrumentos tecnológicos não escolheu o sistema operacional (que seja IOS ou Android), nem que navegador utilizar, pois eles já estão instalados no ato da compra. Após aprender a utiliza-los, dificilmente, em um novo produto, escolherá muda-los. Da mesma forma, tendemos a ser compelidos no uso de Whats $A$ p , se queremos, hoje em dia, comunicar. Essas tecnologias se tornaram naturais e invisíveis, e deslizar as páginas das redes sociais já não é uma escolha, mas um automatismo, incorporando assim o uso das tecnologias nas práticas "naturais" do quotidiano. McLuhan (2011) usa o mito de Narciso para explicar a mídia tradicional, mas a alegoria se aplica bem também às redes sociais: Narciso, espelhando-se na água, apaixona-se pela sua imagem, esquecendo que se trata de uma projeção de si mesmo. Da mesma forma, nos espelhamos nas tecnologias das redes sociais esquecendo que se trata de um produto em parte de nossas escolhas, em parte de outros. Utilizam-se, da mesma maneira que se abre uma torneira e a água sai, sem fazer a pergunta sobre como ou por que. Não se trata de uma visão de determinismo tecnológico, que nos colocaria de forma puramente passiva na aceitação das tecnologias: elas só provocam mudanças na medida em que encontram transformações e expectativas no âmbito da sociedade e da cultura. Sinal claro da naturalização da tecnologia é sua percepção como algo que sempre existia e a dificuldade em entender como era possível viver sem ela.

A forma de falar da tecnologia e de representa-la também contribui a definir seu papel e as consequências que ela tem na sociedade. Em nossa linguagem cotidiana incorpora já há muito tempo a tecnologia, como por exemplo quando dizemos que algo funciona como um relógio, ou que alguém perdeu a bússola. Termos como feedback, ou interface, mais recentes, já fazem parte de nosso vocabulário. Na medida em que a tecnologia não é neutral, da mesma forma não o é a linguagem que usamos sobre ela, enfatizando nossas percepções. É o caso de conteúdos sociais que "viralizam", termo que descreve a passividade dos usuários, de alguma forma destinados a serem infectados pela rápida disseminação de texto, imagens, vídeos.

Uma das narrativas coletivas mais "virais" é a retórica da inovação, que marca - de maneira ideologicamente positiva - o avanço nas tecnologias. Através desse termo, elas se tornam sempre portadoras de bem-estar, instrumento inevitável para a competitividade internacional: a inovação Vem sendo considerada como algo a ser incentivado, fator único e essencial de desenvolvimento e crescimento econômico, silenciando, porém, os fracassos inevitáveis e a imprevisibilidade dos processos de pesquisa, além de não incentivar os questionamentos sobre seus efeitos.

Essa retórica da inovação se articula em um conjunto de termos geralmente utilizados no original inglês, como app, start-up, spin-off. Entre as palavras da tecnologia investidas por um forte valor ideológico, encontrase a palavra-chave smart, prefixo já onipresente: smartphoine, smart $T V$, smart city, smart working. Esse uso tão difundido leva a alguns questionamentos, o mais óbvio dos quais é que os indivíduos do século XXI precisam se sentir smart, isso é, inteligentes. E, para tanto, precisamos usar uno smartphone e não um orelhão. Da mesma forma, é smart reservar um quarto de hotel pela Internet, ou procurar uma carona em uma plataforma digital. Por que fazemos isso? Poupar algum dinheiro ou alguns minutos parece ser um princípio de escasso valor, na medida em que não nos preocupamos em como vamos investir esse tempo e esse dinheiro que poupamos: organizaremos uma outra viagem? Mas isso, de fato, não deveria nos levar a perguntar quais são os impactos dessas escolhas sobre o ambiente, sobre o emprego, sobre as comunidades? Ainda, podemos questionar o deslocamento da palavra: quem é inteligente, de fato, não somos nós, mas os objetos que usamos: usá-los nos 
torna mais inteligentes? Como explica Floridi (2017), o uso contemporâneo do termo Inteligência Artificial é uma cisão entre a capacidade de agir com sucesso para uma finalidade e a necessidade de sermos inteligentes para fazê-los. Temos, assim, uma tecnologia capaz de solucionar problemas complexos sem que, por isso, utilizemos a nossa inteligência. Surge disso um conjunto de implicações muitas vezes pouco consideradas sobre o papel desempenhado pelos algoritmos que selecionam nossos produtos nas redes sociais ou nas grandes plataformas, como Amazon, eBay, Netflix e as várias redes sociais. O uso invasivo de termos como smart se revela um sintoma da tendência a ocultar nossa relação com a tecnologia, pois quando ela nos é apresentada dessa forma, se torna desejável e seu uso passa a ser naturalizado.

Através do uso dessas palavras ligadas à retórica da inovação, traça-se uma linha que marca a adesão coletiva que não deixa possibilidades de escolha. Reconfigura-se, dessa maneira, a ideia de uma tecnologia neutral, minimizando os questionamentos ligados aos impactos das mudanças que ela provoca. Tudo aparenta ser uma atualização mínima a processos e hábitos que já tínhamos: antes se organizavam as viagens com maiores dificuldades, hoje somos mais rápidos e eficientes, assim como acontece com nossos pedidos pelas plataformas de comidas que, antes, pedíamos pelo telefone. Como consequências, poderíamos falar das crises climáticas e sociais que isso provoca, mas a implementação desses termos torna-se de certa forma, um obstáculo na compreensão dessas relações.

O que acontece quando utilizamos essa linguagem, criadora de um mundo tecnológico, é a distorção da perspectiva que nos permite enfocar uma única mudança, no lugar de observarmos o impacto geral: consideramos a inovação como upgrade do presente. O termo upgrade, também parte dessa lista de palavras, é geralmente associado a algo que nossos computadores e celulares realizam automaticamente. Nesse automatismo, porém, acabamos inserindo também nossas práticas sociais e culturais, como revelam as mudanças das mídias tradicionais em sua convergência digital: os usuários, os públicos, continuam a ouvir música e a ler livros e jornais, todos reunidos em um único suporte tecnológicos, mas sem se questionar sobre as mudanças de sentido, de uso que isso provoca.

\section{4 $\mathrm{O}$ atraso da cultura e da política perante as TICs}

O tema do atraso cultural no campo das TICs se evidencia quando percebemos as maneiras como mudaram o comércio, a mobilidade, a informação e as relações sociais. É recente nossa tomada de consciência das consequências para com a privacidade e a concentração de poder nas mãos de poucas e grandes empresas tecnológicas, de forma que a política e a sociedade encontram grandes dificuldades em lidar com o fenômeno das TICs de forma racional. Isso se deve, principalmente, a duas razões:

1) Vimos como as TICs se incorporam facilmente no dia a dia e como se tornam opacas.

2) Percebemos que se tornaram indispensáveis só quando deixam de funcionar (como foi o caso do bloqueio de WhatsApp em 2019).

Além de opacas e naturalizadas, as TICs têm a capacidade de se tornar parte de todas as atividades quotidianas, sejam de trabalho ou tempo livre. A diferença do que acontece com outros serviços essenciais (água, luz, gás), de fato há somente dois gestores (Facebook e Google) agindo em regime de monopólio que, basicamente, impõem suas condições e que, dificilmente, são responsabilizados por eventuais problemas: no caso de insatisfação dos usuários, não há alternativas válidas. Em suma, confiamos as chaves de nossas estruturas a entidades particulares distantes e indefinidas, percebendo tarde demais a irreversibilidade dos processos: trata-se instrumentos planejados para criar dependência informacional, profissional, psicológica. Ainda, com base no vocabulário smart da retórica da inovação, acabamos confundindo a facilidade de seu uso pela consciência das implicações envolvidas em seu uso.

Três aspectos têm sido subestimados pela política e pela sociedade: 
1) O fato que tecnologias de fácil utilização individual - mas com profundas implicações coletivas - fossem colocadas em mãos de privados com alcance monopolista, impedindo a aplicação de regras e sistemas de controle tradicionais.

2) Os serviços oferecidos, aparentemente, são gratuitos (e-mails, navegadores, redes sociais...). As corporações que desenvolveram essa economia tornaram, como vimos, pouco claras as trocas que os usuários aceitam para seu uso: dados, conteúdos e informaçóes pessoais em troca desses serviços.

3) Sobrepomos acessibilidade à transparência, acreditando que navegadores e plataformas tornassem acessíveis, a todos, quantidades ilimitadas de conteúdos gratuitos. Todavia, o algoritmo de seleção de conteúdos de Google é mantido secreto.

As esferas política e social encontram-se, de fato, enredadas em um discurso de determinismo tecnológico, e acabam atribuindo toda mudança positiva ou negativa unicamente à ação da tecnologia, escolhendo, dessa forma, assumir uma postura passiva.

Há duas respostas opostas que são dadas a essa situação:

1) Delega-se à própria tecnologia a solução dos problemas. Podemos ver um exemplo disso na maneira de lidar com conteúdos racistas, machistas, homofóbicos e com as fake News disseminados pelas redes sociais. $\mathrm{O}$ que vem sendo feito é confiar a vigilância sobre os conteúdos a aplicativos e algoritmos desenvolvidos pelas mesmas empresas que possuem as plataformas, evitando, assim, um confronto efetivo com esses processos sociais e históricos.

2) Veta-se o uso de algumas dessas tecnologias. Esse tipo de resposta, também, não é eficaz, na medida em que proibir é complicado pelo fato delas não serem facilmente controláveis nem localizáveis.

Uma das lições ainda a serem aprendidas nesses atrasos culturais em relação à tecnologia é que a sociedade ainda está pouco equipada para enfrentar tamanhos desafios. Não entendemos, por exemplos, a relevância de uma reflexão sobre o futuro de nossas cidades e do meio ambiente em suas relações com as experiências de mobilidade turística moldada pela sinergia entre as viagens low-cost e por empresas digitais como Airbnb ou Amazon. Sem lojas, sem verdadeiras trocas comerciais, sem um tecido cultural sólido, nos encontramos em um mundo empobrecido por dificuldades de moradia e por negócios voltados para a indústria (pesada) do turismo nas mãos desses monopólios digitais.

\section{CONSIDERAÇÕES FINAIS}

Nossa condição atual corresponde, de fato, a uma verdadeira mutação social: a partir da década de 1990, a tecnologia deixou de ocupar somente os espaços sociais a elas destinados, para se infiltrar em todas as estruturas e, no limite, ocultar seus aparatos. Ao mesmo tempo, a tecnologia tem penetrado as estruturas e as experiências dos indivíduos e grupos de tal forma que constituiu ambientes híbridos e criou formas visíveis e invisíveis de interação, até se instalar nas próprias estruturas biológicas. Tal disseminação tem provocado a eliminação da clássica oposição entre "natural" e "artificial", instrumento cultural de interpretação da experiência. Certo, de maneira convencional, continuamos opondo a natureza à tecnologia, mas a realidade nos diz que essa ideia pertence a um outro momento.

Se queremos que as novas mídias tragam mais benefícios que desapontamentos, temos que enfrentá-las com maior consciência e menos ilusão sobre sua capacidade de serem smart.

A mídia, hoje, não se encontra mais em momentos e lugares distintos, nem representa algo no âmbito do qual podemos distinguir a natureza da tecnologia, na medida em que se fundiu em aparatos tão diferentes e presentes até se tornar um continuum em nossas vidas. A tecnologia está sempre presente, seja para explorar recursos, ou para a segurança e o controle, ou para o transporte e o comércio, revelando a presença de elementos e funções que, antes, eram específicos da mídia - na capacidade de registrar, memorizar, manipular, 
disseminar e permitir a recepção de informações. Eis, então, que o filme Avatar amplia, finalmente, seu sentido, para nos falar da naturalização desse novo paradigma ideológico: na medida em que a "velha" tecnologia humana entra em oposição com a natureza, descobrimos que essa última se identifica com a estrutura tecnológica digital que nos permeia.

\section{REFERÊNCIAS}

Almeida, M. A. e Crippa, G. (2009). De Bacon à internet: considerações sobre organização do conhecimento e a constituição da ciência da informação. Ponto de acesso, 3(2), 109-131. Recuperado de https://periodi index.php/ revistaici/article/view/3284.

Banti, A. M. (2017). Wonderland: la cultura di massa da Walt Disney ai Pink Floyd. Bari: Laterza.

Briggs, A. e Burke, P. (2002). Storia sociale dei media: da Gutemberg a Internet. Bologna: Il Mulino.

Castells, M. (2001). Galassia Internet. Milano: Feltrinelli.

Durand, G. (2012). L'immaginazione simbolica. Milano: Ipoc.

Floridi, L. (2017). La quarta rivoluzione. Milano: Cortina.

Hajdu, D. (2008). Maledetti fumetti: come la grande paura per i "giornaletti" cambiò la società statunitense. Latina: Tunuè.

Jenkins, H. (2009). Cultura da convergência. São Paulo: Aleph.

Lastres H. e Albagli, S. (Orgs.) (1999). Informação e globalização na era do conhecimento. Rio de Janeiro: Campus.

Le Goff, J. (1993). L'immaginario medievale. Milano: Mondadori.

Lemos, A. (2011). Mobilidade e espaço urbano. In G. Beiguelman \& J. La Ferla, Nomadismos tecnológicos (pp. 15-34). São Paulo: SESC.

Massidda, L. (2011). Atlante delle grandi esposizioni universali: storia e geografia del medium espositivo. Milano: Franco Angeli.

Mattelart, A. (2002). História da utopia planetária. Porto Alegre: Sulina.

McLuhan, M. (2011). Capire i media. Gli strumenti del comunicare. Milano: Il Saggiatore.

Starri, M. (2019). Digital 2019: tre italiani su cinque attivi sui social per quasi due ore al giorno. Recuperado de http:/ /wearesocial.com/it/blog/2019/01/digital-in-2019. 